\title{
Self-determination theory goes public: experimental evidence on the causal relationship between psychological needs and job satisfaction
}

\section{R. Paul Battaglio, Nicola Belle \& Paola Cantarelli}

To cite this article: R. Paul Battaglio, Nicola Belle \& Paola Cantarelli (2021): Self-determination theory goes public: experimental evidence on the causal relationship between psychological needs and job satisfaction, Public Management Review, DOI: 10.1080/14719037.2021.1900351

To link to this article: https://doi.org/10.1080/14719037.2021.1900351

\section{曲 Published online: 25 Mar 2021.}

Submit your article to this journal $\widetilde{x}$

Q View related articles $\sqsubset$

View Crossmark data $\asymp$ 


\title{
Self-determination theory goes public: experimental evidence on the causal relationship between psychological needs and job satisfaction
}

\author{
R. Paul Battaglio (iD ${ }^{a, b}$, Nicola Belle ${ }^{b}$ and Paola Cantarellib \\ aUniversity of Texas at Dallas, Richardson, TX, USA; 'SCuola Superiore Sant'Anna, Pisa, Italy
}

\begin{abstract}
This study puts self-determination theory to an empirical test through a series of discrete choice experiments across three samples of public healthcare workers, for a total of 4,743 subjects. The three replications provide convergent evidence in support of the hypotheses that autonomy, competence, and three types of relatedness - with supervisors, peers, and beneficiaries - simultaneously and independently increase employee satisfaction. Meaningful differences emerge in the relative importance of those five factors. In particular, the fulfilment of one's need for competence turns out to have the greatest positive impact across experimental replications, whereas the need for autonomy consistently comes last.
\end{abstract}

KEYWORDS Self-determination theory; job satisfaction; behavioural public administration; conjoint analysis; public employees

"All employees have three basic psychological needs - for competence, autonomy, and relatedness - the satisfaction of which promotes autonomous motivation, high-quality performance, and wellness"

- Deci, Olafsen, and Ryan 2017, 19 -

Work motivation and job satisfaction are two of the most popular constructs in contemporary general management (e.g. Bolino and Grant 2016), organizational psychology (e.g. Deci, Olafsen, and Ryan 2017), and public administration (e.g. Perry, Hondeghem, and Wise 2010). Studies into the motivational bases of public service have flourished over three decades, spurred by nascent public service motivation research (e.g. Perry and Wise 1990) - a topic which has drawn thrived like few other topics within our field (e.g. Belle 2013, 2014; Belle and Cantarelli 2015, 2019; Christensen, Paarlberg, and Perry 2017; Linos 2018; Marvel and Resh 2018; Ritz, Brewer, and Neumann 2016; Meyer-Sahling, Mikkelsen, and Schuster 2019; Vandenabeele 2007; Wright and Grant 2010). Public administration scholars (e.g. Cantarelli, Belle, and Longo 2020; Mergel, Belle, and Nasi 2019) have recently integrated public service motivation into self-determination theory (Deci and Ryan 2000). Thanks to its comprehensiveness, self-determination theory has rapidly become well established and is rapidly gaining popularity across the social sciences (e.g. Deci, Olafsen, and Ryan 
2017; Vandenabeele 2014). Using self-determination theory as a theoretical lens to investigate public employees' well-being may help avoid the segregation of public personnel administration scholarship from the mainstream human resource management literature.

With respect to job satisfaction, 'thousands of studies and dozens of different questionnaire measures have made job satisfaction one of the most intensively studied variables in organizational research, if not the most studied' (Rainey 2009, 298). The first metaanalysis of the public administration literature on job satisfaction identified 43 unique job satisfaction correlates from a sample of 99 studies published in 42 peer-reviewed Englishlanguage public administration journals listed by the 2013 ISI Journal Citation Reports (Cantarelli, Belardinelli, and Belle 2016). Research into the correlational variables and causal antecedents of job satisfaction has proven fruitful among scholars and practitioners alike (e.g. An et al. 2020; Breaugh, Ritz, and Alfes 2018; Chordiya, Sabharwal, and Paul Battaglio 2019; Langer, Feeney, and Lee 2019; Lee, Robertson, and Kim 2020; Steijn and van der Voet 2019; Vigan and Giauque 2018).

Nonetheless, the causal relationship between basic psychological needs and job satisfaction remains largely obscure because of a series of methodological limitations, such as a reliance on correlational data that impinges on the internal validity of results, threats to construct validity stemming from the use of un-comprehensive operations for psychological needs, and threats to external validity due to the paucity of study replications across units and settings (e.g. Walker et al. 2019; Zhu, Witko, and Meier 2019). To fill these gaps, our study employs a series of discrete choice experiments across organizations to test the relative importance of the fulfilment or frustration of the psychological needs encompassed in self-determination theory on public employees' stated job satisfaction.

Our study provides the following main contributions. Firstly, to the best of our knowledge, no previous work has entailed a comprehensive test of self-determination theory using large-scale randomized experiments with real public professionals. The nature of our sample, thus, seems to provide a unique stage for testing the potential of self-determination theory for advancing public management research. In particular, we take up the call of behavioural public administration scholars (e.g. Battaglio et al. 2019) to draw on insights from psychology to tackle public management issues using settings that are 'a real-life laboratory to study human judgment and decision making in which the ecological validity and practical implications of psychological theories can be tested' (Grimmelikhuijsen et al. 2017, 53). A second contribution lies in disentangling the simultaneous and independent effects that the fulfilment or frustration of the three psychological needs for autonomy, competence, and relatedness may have on public professionals' job satisfaction. As far as relatedness is concerned, we break down the need for belonging to others into distinct operations for supervisors, peers, and beneficiaries of one's work. Moreover, our experimental design provides a robust test of the external validity of the findings through replications across different public employees and healthcare systems.

\section{Theoretical background and hypotheses}

\section{Self-determination theory in the context of public administration}

At its core, self-determination theory suggests that individuals have three basic psychological needs, namely for autonomy, competence, and relatedness. Autonomy 
refers to the 'desire to self-organize experience and behavior and to have activity be concordant with one's integrated sense of self (Deci and Ryan 2000, 231). Competence is linked to the necessity of having 'an effect on the environment as well as to attain valued outcomes within it' (Deci and Ryan 2000, 231). Relatedness is the 'desire to feel connected to others - to love and care, and to be loved and cared for' (Deci and Ryan 2000,231 ). As long as employees simultaneously feel autonomous, competent, and related to others, they are psychologically healthy, and their behaviour is intrinsically motivated. As some of those basic needs go unmet, behaviour is extrinsically motivated by progressively less self-determined types of regulations, ranging from identified to purely external. In their recent attempt to systematize knowledge, Deci, Olafsen, and Ryan (2017) depict a basic model of self-determination theory in the workplace. In that model, the causal effect of workplace context and individual characteristics on work behaviours and employees' health and wellness is mediated through the satisfaction or frustration of the basic psychological needs and the degree to which motivations are autonomously determined or controlled. The work behaviour outcomes include performance quality and performance quantity, while workers' health and wellness include well-being, vitality, and ill-being. Thus, the framework simultaneously takes into account 'the dual concerns of performance and wellness in organizations' (Deci, Olafsen, and Ryan 2017, 20). Within this framework, our study adopts an experimental approach to investigate a relatively underexplored relationship, namely the causal link between the fulfilment or frustration of employees' basic psychological needs and their job satisfaction.

Public management scholarship that capitalizes on research into psychological needs is still at its infancy. For instance, very recent theoretical work of Corduneanu, Dudau, and Kominis (2020) proposes that the satisfaction of the basic psychological needs may mediate the relationship between performance-related rewards and public service motivation. Earlier theoretical work claims that as long as institutions satisfy employees' need for autonomy, competence, and relatedness, then civil servant will internalize institutionalized public service values more autonomously (Vandenabeele 2007). The observational survey of Vandenabeele (2014), then, show that the fulfilment of autonomy and competence - but not relatedness - strengthen the positive association between leaders' who promote public values and followers' public service motivation. Other empirical work demonstrates that the fulfilment of psychological needs for autonomy, competence, and relatedness is positively related to engagement. Moreover, meaningful relations at work seem to have the potential for mitigating the negative association between stress and engagement (Breaugh 2020).

In addition to systematizing individuals' psychological needs, self-determination theory distinguishes between intrinsic and extrinsic types of motivation. Over the last few years, a number of studies have attempted to reconcile and integrate selfdetermination theory with the construct of public service motivation, which is native to our field (Perry and Wise 1990). In particular, public administration scholars have been using self-determination theory to disentangle the intrinsic, prosocial, and purely extrinsic motives that drive job preferences among civil servants (Belle and Cantarelli 2015; Chen and Bozeman 2013), public nurses (Cantarelli, Belle, and Longo 2020), private sector IT professionals joining government (Mergel, Belle, and Nasi 2019), and public school teachers (Jacobsen, Hvitved, and Andersen 2014). Recently, Breaugh, Ritz, and Alfes (2018) found that public employees' job satisfaction is positively correlated with intrinsic and integrated regulations and not correlated with introjected and external regulations. 
Extant public management scholarship, thus, seems to lack comprehensive operations for the psychological needs for autonomy, competence, and relatedness, as well as the causal impact that their fulfilment generates on workers' satisfaction. In other words, whereas several public administration studies have drawn on selfdetermination theory to distinguish between intrinsic and extrinsic types of motives in the context of public service (e.g. Breaugh, Ritz, and Alfes 2018; Steijn and van der Voet 2019), our work is the first in our field that experimentally manipulates the three psychological needs that constitute the root cause of those motives. From a methodological perspective, to the best of our knowledge, no randomized experiment have targeted the fulfilment of psychological needs in public administration settings. Moreover, unlike previous work that used a single lens in looking at the need for feeling connected to others (e,g., Jensen and Bro 2018), we broke down the relatedness construct into the distinct needs for maintaining a fulfiling connection with supervisors, peers, and clients. The rationale for including these three types of relations is twofold. From a theoretical standpoint, previous work in this area has differentiated among the different categories of individuals and different beneficiaries with which public employees interact at work (e.g. Belle 2014; Breaugh 2020; Deci, Olafsen, and Ryan 2017; Grant 2007). From a practical standpoint, virtually every public employee has a supervisor, some peers, and some clients, either internal or external to their organization. Therefore, we think it is important to disentangle the simultaneous and independent effects that these ubiquitous relations have on public workers' satisfaction. On the contrary, conflating these profoundly different types of interactions into one single operation might generate threats to construct validity, thus impinging on the usefulness of our findings to inform human resource management practices in public organizations.

\section{Job satisfaction in the context of public administration}

In times when governments around the world struggle with plans to cut back on personnel and with efforts to maximize the effectiveness of personnel policies, public managers have the moral duty to enhance the productivity of their remaining employees to ensure that essential services are adequately provided. Making civil servants satisfied with and committed to their jobs is one of the preconditions of reaching this goal. Meta-analytically summarizing knowledge about whether and to what degree different variables relate with public employees' job satisfaction has caught scholars' attention in recent years (e.g. Cantarelli, Belardinelli, and Belle 2016; Vigan and Giauque 2018) and does not seem to have come to an end. Indeed, job satisfaction 'is one of the most important workplace attitudes [and] an important element of employees' mental health and overall well-being' (Yang and Kassekert 2009, 414).

Different disciplines (e.g. public administration, mainstream management, and applied psychology) within the social sciences seems to agree on the fact that job satisfaction simultaneously entails the fulfilment of individual needs that vary over time and the fit with organization-level characteristics that also vary over time (Rainey 2009). Whereas early definitions in mainstream management and psychology describe job satisfaction as 'the feelings a worker has about his job' (Smith, Kendall, and Hulin $1969,100)$ or as 'a pleasurable or positive emotional state, resulting from the appraisal of one's job or job experiences' (Locke 1976, 1304), extant definitions in public administration highlight that job satisfaction is an 'affective or emotional response 
with various facets of one's job' (Kim 2005, 246) or it relates to 'how an individual feels about his or her job and various aspects of it usually in the sense of how favorable how positive or negative - those feelings are' (Rainey 2009, 298).

Based on the relative definition adopted, job satisfaction is typically measured through a single Likert-type item or through an index combining more items. The Federal Employee Viewpoint Survey (United States Office of Personnel Management), which is extensively used in public administration research (e.g. Fernandez et al. 2015), measures job satisfaction in terms of both overall feeling and specific facets. In all cases, satisfaction with one's job in public organizations tends to be an individual's selfreported stated measure (Cantarelli, Belardinelli, and Belle 2016).

\section{Fulfilment of basic psychological needs and job satisfaction}

A meta-analytic synthesis of studies across disciplines that is published in a management journal finds that the fulfilment of each of the three selfdetermination theory psychological needs at work account for unique variation in job satisfaction and explain $50 \%$ of the variance overall. In particular, a relative weights analysis showed that autonomy predicted about $55 \%$ of the job satisfaction variance, relatedness about 23\%, and competence about 22\% (Van den Broeck et al. 2016). To the best of our knowledge, no work has been conducted in the context of public organizations that simultaneously analyzes the relationships between each of those three psychological needs and job satisfaction, nor the relative importance and tradeoffs between those needs. To help fill this gap, we formulate and test the following hypotheses on a series of large- $\mathrm{N}$ discrete choice experiments with public employees:

Hp 1: Public employees are more satisfied in job settings in which their need for autonomy is fulfilled to a larger rather than a smaller extent.

Hp 2: Public employees are more satisfied in job settings in which their need for competence is fulfilled to a larger rather than a smaller extent.

Hp 3: Public employees are more satisfied in job settings in which their need for relatedness with clients is fulfilled to a larger rather than a smaller extent.

Hp 4: Public employees are more satisfied in job settings in which their need for relatedness with peers is fulfilled to a larger rather than a smaller extent.

Hp 5: Public employees are more satisfied in job settings in which their need for relatedness with supervisors is fulfilled to a larger rather than a smaller extent.

While individuals can intuitively be expected to prefer work environments that offer more opportunities to meet each of these five needs, there is no conclusive evidence as to the relative importance of these factors. In addition to the theoretical relevance, this can be important for public organizations and their managers who, in the face of limited resources, cannot improve all dimensions together, but on the contrary must establish priorities for intervention.

In developing our theoretical framework and our empirical strategy, we made several judgements. Two of the most consequential decisions concern the choice to 
focus only on the theory of self-determination and to the selection of study operations over competing alternatives. Although these choices were guided by precise reasons, which we try to illustrate and justify in the article, a space of subjectivity is still inevitable.

\section{Research design and methods}

\section{Discrete choice experiment}

This study consists of three discrete choice experiments (DCEs). This research design has recently gained popularity among public administration scholars, who have used DCEs to elicit preferences and estimate the relative importance of factors that simultaneously affect choices between, for example, governance systems (Van Puyvelde et al. 2016), job positions (e.g. Cantarelli, Belle, and Longo 2020; Belle and Cantarelli 2018b), job candidates (Jankowski, Prokop, and Tepe 2020; MeyerSahling, Mikkelsen, and Schuster 2020), public service providers (Jilke, Van Ryzin, and Van de Walle 2016), contact-tracing apps (Horvath, Banducci, and James 2020), citizens to prioritize (Jilke and Tummers 2018), misbehaviours (Belle and Cantarelli 2019; Schuster, Jan-Hinrik, and Mikkelsen 2020), and work incidents to report (Jensen and Pedersen 2017). Unlike other experimental designs, DCEs are particularly well suited for modelling real-world decisions that entail trade-offs (e.g. Hainmueller, Hangartner, and Yamamoto 2015; Ryan et al. 2012), such as those faced by public employees called to choose between different job opportunities, training programmes, and the like. In this type of choices, alternatives are bundles of attributes that differ along multiple dimensions, rather than a single factor. For instance, when choosing between job offers, candidates take into account simultaneously such features as salary, hours, distance from home, the type of activities that are required, and so on (Belle and Cantarelli 2018a).

Our DCE is a paired conjoint design with a forced choice that entails presenting respondents with a pair of alternatives (i.e. a choice-set) that differ along multiple attributes and asking to choose the preferred option. Conjoint analysis presents several advantages compared to traditional survey experiments, such as vignettes. In particular, Hainmueller, Hopkins, and Yamamoto (2014) argue that by exposing subjects to multiple pieces of information at once, conjoint analysis provides an enhanced realism relative to survey instruments that elicit preferences on single pieces of information at a time. This makes conjoint analysis less artificial than traditional survey experiments and thus better suited for capturing decision-making in information-rich environments such as those facing individuals making real-world choices. Secondly, conjoint analysis may be more efficient than classic vignettes because it allows estimating the simultaneous and relative effects of a larger number of attributes on a single behavioural outcome, thus making it more practical to move beyond single theory and/or hypothesis testing. Moreover, conjoint analysis mitigates concerns about social desirability as the multiplicity of attributes gives respondents more opportunities to justify any particular choice and relieves them of social pressure. Lastly, the ability of conjoint analysis to indicate the most preferred combination of a number of attributes can provide useful insights for a variety of public policy and management issues, including the design of services that meet citizens' expectations or the design of human resource polices that nurture employees' satisfaction. 
Table 1 shows the attributes and the attribute levels that we used across our three DCEs. More precisely, the first column reports our five target-constructs and the second column indicates the corresponding two-level operation for each targetconstruct. The two levels of each attribute are intended to trigger subjects' sense of fulfilment or frustration, respectively, of the underlying psychological need.

Based on well-established guidelines in crafting discrete choice experiments (e.g. Ryan et al. 2012), we built on the theoretical definition of each psychological need to design attribute-levels. To strengthen ecological validity (Morton and Williams 2010), we conducted focus groups with more than 100 public healthcare managers from all specialities and departments, and multiple meetings with policy makers and public healthcare experts to refine and validate our operations.

The combination of the five attributes with two levels each generated 32 (i.e. 25) unique job scenarios. Using a full factorial design, we kept all 32 combinations derived from the full set of attributes and levels. This procedure avoided any restrictions on the possible attribute combinations, thus making the attributes mutually independent (Hainmueller, Hopkins, and Yamamoto 2014). Using the cyclical fold-over technique proposed by Street, Burgess, and Louviere (2005), then, we created 32 choice-sets by pairing each job scenario with its mirror alternative. Thus, within each pair of options, the levels in one job scenario are the exact opposite of the levels in the mirror scenario across all five attributes. For instance, for a situation in which the worker has low decision autonomy, full competence to successfully carry out the job tasks, a positive impact on many clients, is little satisfied with the relationship with their peers, and satisfied with the relationship with the supervisor, the mirror situation would be one in which the worker has high decision autonomy, does not have the competence to successfully carry out some of the job tasks, has a positive impact on a few clients, is satisfied with the relationship with their peers, and little satisfied with the relationship with the supervisor. As an example, Appendix A reports two of those 32 choices sets. Fold-over designs minimize overlap because 'within any choice the attribute level is not repeated across options' (Ryan et al. 2012, 24).

As to limit cognitive fatigue and avoid overload, we made the following decisions. Firstly, each public employee in our samples is only presented with one choice set, selected at random from all 32 possible choice sets. The random assignment of participants to choice sets strengthens the internal validity of our inference by eliminating the risk of 'systematic differences over conditions in respondents

Table 1. Attributes and attribute levels for all DCEs.

\begin{tabular}{ll}
\hline $\begin{array}{l}\text { ATTRIBUTE } \\
\text { (Target construct) }\end{array}$ & \multicolumn{1}{c}{$\begin{array}{c}\text { LEVELS } \\
\text { (Operations for target construct) }\end{array}$} \\
\hline $\begin{array}{l}\text { Autonomy } \\
\text { Competence }\end{array}$ & $\begin{array}{l}\text { You have high (low) decision-making autonomy. } \\
\text { You have (do not have) the competence to carry out successfully all (some of) } \\
\text { the tasks required by your job. } \\
\begin{array}{l}\text { Relatedness with } \\
\text { beneficiaries }\end{array}\end{array}$ \\
$\begin{array}{l}\text { Relatedness with peers } \\
\text { Relatedness with supervisor }\end{array}$ & $\begin{array}{l}\text { You are (little) satisfied with the relationship with your peers. } \\
\text { You are (little) satisfied with the relationship with your supervisor. }\end{array}$ \\
\hline
\end{tabular}


characteristics that could also cause the observed effect' (Shadish, Cook, and Campbell 2002, 55). Secondly, after being presented with a pair of workplace scenarios, the respondent only has to choose the one in which he or she would feel more satisfied (i.e. paired conjoint design with a forced choice).

Because the dependent variable in our DCEs is binary, following the guidelines by Ryan et al. (2012), we fitted a conditional logit model, which is required to analyse stacked data where we have two rows for each choice set. Conditional logistic regression 'will yield exactly the same results as the binary logit' (Ryan et al. 2012, 57). Regression results (i) provide information about the relative impact of each attribute on participants' choice and (ii) control for the characteristic of the alternative that is not selected. Field evidence on factors trade-offs hold the promise of being particularly useful when limited resources do not allow offering a superior option with the best levels of all the factors, which often is the case in public organizations.

DCE 1 aims at testing the job satisfaction effects of the fulfilment or frustration of the basic psychological needs that are at the core of self-determination theory - namely autonomy, competence, and relatedness - among real public employees serving mission-driven organizations in one healthcare system. DCE $2 a$ and DCE $2 b$, then, aims at testing the external validity of the findings of DCE 1 by varying subjects and the environment (i.e. the healthcare system) and keeping every other characteristic of the study design equal. DCE $2 \mathrm{a}$ and DCE $2 \mathrm{~b}$ are two different waves of the experimental survey in another healthcare system.

\section{Participants and procedures}

All participants are civil servants working for public healthcare organizations in two Regions in Italy. Subjects in DCE 1 are 3,242 public employees serving the healthcare system of Region 1. As far as gender is concerned, $70 \%$ of the sample is female and $30 \%$ male. As for age, $17 \%$ of the sample is younger than 25, 24\% is between 25 and 34 years old, $37 \%$ is between 35 and 44 years old, and 22\% is between 45 and 54 years old. As far as the job family is concerned, respondents are split as follows: $59 \%$ are nurses or nurses assistants, $14 \%$ medical doctors, $13 \%$ administrative personnel, and $10 \%$ technicians. As for the type of organizations, $62 \%$ of the subjects work in hospital settings, $23 \%$ serve local health authorities, and $14 \%$ are employed by teaching hospitals.

Participants in DCE 2a and 2b are 953 and 548, respectively, public employees serving the healthcare system of Region 2. In DCE $2 a$, as far as gender is concerned, $56 \%$ of the sample is female and $43 \%$ male. As for age, $8 \%$ of the sample is younger than $25,21 \%$ is between 25 and 34 years old, $34 \%$ is between 35 and 44 years old, and $36 \%$ is between 45 and 54 years old. The distribution of respondents by job family is as follows: $45 \%$ are nurses or nurses assistants, $20 \%$ medical doctors, $18 \%$ administrative personnel, and $10 \%$ technical staff. As for the type of organizations, $67 \%$ of the subjects work for local health authorities, $28 \%$ are employed by teaching hospitals, and $5 \%$ serve cancer centres. In DCE $2 \mathrm{~b}$, as far as gender is concerned, $55 \%$ of the sample is female and $45 \%$ male. As for age, $7 \%$ of the sample is younger than $25,21 \%$ is between 25 and 34 years old, $35 \%$ is between 35 and 44 years old, and 36\% is between 45 and 54 years old. Based on the job family, respondents are split as follows: $46 \%$ are nurses or nurses assistants, $22 \%$ medical doctors, $14 \%$ technicians, and $13 \%$ administrative staff. As for 
the type of organizations, $77 \%$ of the subjects work for local health authorities, $16 \%$ is employed by teaching hospitals, and $4 \%$ serves cancer centres.

Both Region 1 and Region 2 are members of a voluntary group of Italian regional healthcare systems that regularly measure employees' perceptions about their job through an online survey that is administered by the Healthcare Management Lab of the Sant'Anna School of Advanced Studies (Italy). The organizational climate survey has two main sections. Building on the Federal Employee Viewpoint Survey (e.g. Fernandez et al. 2015) and similar experiences of governments and public organizations around the world (e.g. OECD 2016), the first section employs a cross-sectional quantitative design to measure such variables as job engagement, intent to leave, satisfaction with training programs, and satisfaction with the organization of work. The second section of the organizational climate survey, instead, uses online experiments to investigate such questions as how do the fulfilment of psychological needs affect employees job satisfaction. All DCEs in our study were part of this second section. Data were collected in March-April 2019 for DCE 1, May-June 2019 for DCE 2a, and July-August for DCE $2 \mathrm{~b}$.

The next section illustrates our results, which were previously presented and discussed in a workshop with more than 100 healthcare professionals so as to gauge ecological validity based on the extent to which the findings that we obtained in our research environment resonate with target real-world contexts (Harrison and List 2004; Morton and Williams 2010). Public manager and employees in the workshop easily identified themselves and their working conditions with our experimental environment and operations.

\section{Results}

Tables 2-4 show the conditional logistic regression results for the DCEs in our study. For each of the five attributes in each wave of the DCEs, the table displays the following items: unstandardized raw coefficients (b), standard errors (SE), z-scores (z), $p$-values $(p>z)$, odds ratios $\left(e^{\wedge} b\right)$, and percentage change in odds when the corresponding attribute varies from one level to the next. A positive and significant coefficient implies that the attribute has a positive effect on the take-up of a given option; a negative and significant coefficient implies the opposite.

The analysis of the data from DCE 1 (Table 2) reveals that, other things being equal, the odds that public employees would be more satisfied in a job situation rise by 49 percentage points when they have greater decision making autonomy $(p<.0005)$, by 200 percentage points when they are more competent $(p<.0005)$, by 125 percentage

Table 2. Estimates from a conditional logit model - discrete choice experiment 1.

\begin{tabular}{lccccccc}
\hline TARGET NEED & $\mathrm{b}$ & $\mathrm{SE}$ & $\mathrm{z}$ & $p>z$ & $95 \%$ C.I. & $\mathrm{e}^{\wedge} \mathrm{b}$ & $\%$ \\
\hline Autonomy & .40 & .05 & 8.94 & .000 & $(.31 ; .49)$ & 1.49 & 49 \\
Competence & 1.10 & .05 & 22.65 & .000 & $(1.00 ; 1.19)$ & 3.00 & 200 \\
Relatedness with beneficiaries & .81 & .05 & 17.29 & .000 & $(.72 ; .90)$ & 2.25 & 125 \\
Relatedness with peers & .82 & .05 & 17.40 & .000 & $(.72 ; .91)$ & 2.27 & 126 \\
Relatedness with supervisor & .61 & .05 & 13.35 & .000 & $(.52 ; .70)$ & 1.84 & 84 \\
Constant & .00 & .04 & -.10 & .921 & & & \\
Number of respondents & 3,242 & & & & & & \\
X2 & 1356 & & & & & & \\
Prob $>$ X2 & .000 & & & & & & \\
\hline
\end{tabular}


Table 3. Estimates from a conditional logit model - discrete choice experiment 2a.

\begin{tabular}{lllrlrcc}
\hline TARGET NEED & $\mathrm{b}$ & $\mathrm{SE}$ & $\mathrm{z}$ & $p>z$ & $95 \%$ C.I. & $\mathrm{e}^{\wedge} \mathrm{b}$ & $\%$ \\
\hline Autonomy & .28 & .07 & 3.78 & .000 & $(.13 ; .43)$ & 1.32 & 32 \\
Competence & .78 & .08 & 10.29 & .000 & $(.64 ; .93)$ & 2.18 & 119 \\
Relatedness with beneficiaries & .56 & .08 & 7.41 & .000 & $(.41 ; 71)$ & 1.75 & 75 \\
Relatedness with peers & .49 & .07 & 6.50 & .000 & $(.34 ; .64)$ & 1.63 & 63 \\
Relatedness with supervisor & .35 & .07 & 4.72 & .000 & $(.21 ; .50)$ & 1.42 & 42 \\
Constant & -1.14 & .07 & -1.87 & .061 & & & \\
Number of respondents & 953 & & & & & & \\
X2 & 239 & & & & & & \\
Prob $>X 2$ & .000 & & & & & & \\
\hline
\end{tabular}

Table 4. Estimates from a conditional logit model - discrete choice experiment 2b.

\begin{tabular}{lccccccc}
\hline TARGET NEED & $\mathrm{b}$ & $\mathrm{SE}$ & $\mathrm{z}$ & $p>z$ & $95 \%$ C.I. & $\mathrm{e}^{\wedge} \mathrm{b}$ & $\%$ \\
\hline Autonomy & .32 & .10 & 3.27 & .001 & $(.13 ; .52)$ & 1.38 & 38 \\
Competence & .87 & .10 & 8.44 & .000 & $(.67 ; 1.07)$ & 2.39 & 138 \\
Relatedness with beneficiaries & .67 & .10 & 6.56 & .000 & $(.47 ; .87)$ & 1.95 & 95 \\
Relatedness with peers & .34 & .10 & 3.44 & .001 & $(.15 ; .54)$ & 1.40 & 41 \\
Relatedness with supervisor & .32 & .10 & 3.26 & .001 & $(.13 ; .52)$ & 1.38 & 38 \\
Constant & .08 & .10 & .82 & .412 & & & \\
Number of respondents & 548 & & & & & & \\
$X 2$ & 149 & & & & & & \\
Prob $>X 2$ & .000 & & & & & & \\
\hline
\end{tabular}

points when they feel higher relatedness with beneficiaries $(p<.0005), 126$ percentage points when they feel higher relatedness with peers $(p<.0005)$, and 84 percentage points when they perceive higher relatedness with their supervisor $(p<.0005)$. Thus, DCE 1 seems to support hypotheses 1 through 5 .

Any two given coefficients are significantly different at the .001 level, except for the coefficients on relatedness with beneficiaries and relatedness with peers, which are not distinguishable from each other $(p=.923)$.

Findings from DCE 2 a replicate the same pattern of results as DCE 1 (Table 3). Similar to respondents in DCE 1, as hypothesized, public employees in DCE 2 a are more likely to be satisfied in a job scenario in which they have more competencies, have a positive effect on more people, have larger autonomy, are more satisfied with their peers, and are more satisfied with their supervisor. In particular, in DCE $2 \mathrm{a}$, the odds that public employees would choose a job scenario to be more satisfied increase by $32 \%$ when they have high rather than low decision-making autonomy $(p<.0005)$, $119 \%$ when they have the competence to carry out successfully all the job tasks rather than when they do not have the competence to carry out some of the job tasks $(p<.0005), 75 \%$ when they have a positive impact on many rather than a few clients $(p<.0005), 63 \%$ when they are satisfied instead of little satisfied with the relationship with their peers $(p<.0005)$, and $42 \%$ when they are satisfied instead of little satisfied with the relationship with their supervisor $(p<.0005)$.

The relative importance of attributes in affecting job choice show some differences in DCE2a as compared to DCE 1. Any two coefficients are statistically different from each other at the .05 significance level, except for the following pairs: autonomy and relatedness with supervisor $(p=.487)$, relatedness with beneficiaries and with peers $(p=.485)$, and relatedness with colleagues and with supervisor $(p=.179)$. 
The pattern of results from DCE $2 \mathrm{~b}$ mirrors that from DCE 2a (Table 4). More precisely, the odds that public workers in DCE $2 \mathrm{~b}$ would be more satisfied in a given job setting rise by 38 percentage points when the need for autonomy is fulfilled rather than frustrated $(p=.001), 138$ percentage points when the need for competence is fulfilled rather than frustrated $(p<.0005), 95$ percentage points when the need for relatedness with beneficiaries is fulfilled rather than frustrated $(p<.0005), 41$ percentage points when the need for relatedness with peers is fulfilled rather than frustrated $(p=.001)$, and 38 percentage points when the need for relatedness with one's supervisor is fulfilled rather than frustrated $(p<.0005)$. Therefore, hypotheses $1,2,3,4$, and 5 seem to also find full support in DCE $2 b$.

Any two coefficients are statistically different from each other at the .05 significance level, except for the following pairs: autonomy and relatedness with supervisor $(p=.997)$, autonomy and relatedness with peers $(p=.898)$, competence and relatedness with beneficiaries $(p=.112)$, relatedness with peers and with supervisor $(p=.897)$.

To sum up, all five attributes have the expected effect on subjects' choices across all three DCEs, thus fully supporting our hypotheses. However, significant differences emerge in the relative importance of the five attributes, with their relative strength changing across trials. Based on our results, the need for competence seems the strongest determinant of job satisfaction because the corresponding coefficients turns out to be the largest across the board, alone or on an equal footing with the need for relatedness with beneficiaries. On the other end of the spectrum, quite unexpectedly, the need for autonomy consistently ranks as the least important attribute, alone or in conjunction with others.

\section{Discussion}

Findings from identical discrete choice experiments - replicated three times across two healthcare systems - consistently show that public professionals are more likely to feel satisfied in work settings that provide greater autonomy, competence, and relatedness with beneficiaries, peers, and supervisors. Across replications, the fulfilment - instead of the frustration - of the need for competence tend to be the strongest psychological determinant of job satisfaction, whereas the satisfaction - instead of the dissatisfaction - of the need for autonomy seem to have the smallest impact. This ranking seems to differ from the work of Van den Broeck et al. (2016). Whereas the effects of psychological determinants on job satisfaction are all significant and in the expected direction, their size vary across the three discrete choice experiments (see Appendix B for a graphical representation).

Our research aspires to provide a number of contributions which however must be interpreted in light of possible threats to the ecological validity of our inference that arise from the use of simulated rather than real decisions. The first contribution of our work is of a theoretical nature. Based on the model of self-determination theory in the workplace (Deci, Olafsen, and Ryan 2017), most public administration scholarship has investigated how motivations - for instance, intrinsic, prosocial, and extrinsic regulations - affect work behaviours such as different performance dimensions (e.g. Belle 2013, 2014; Meyer-Sahling, Mikkelsen, and Schuster 2019). To the contrary, extant theoretical and empirical work of psychological needs in public human reource management is scant (Breaugh 2020; Corduneanu, Dudau, and Kominis 2020; 
Vandenabeele 2007, 2014). We expand this research stream and contribute to the flourishing scholarship in behavioural public administration (e.g. Battaglio et al. 2019; Grimmelikhuijsen et al. 2017) by investigating the causal link between the fulfilment of basic psychological needs - for autonomy, competence, and relatedness - and health and wellness outcomes - such as satisfaction - in the workplace.

The second contribution of our work is nurtured by two features of the operations of the independent variables. Firstly, the levels of each of the attributes improve our understanding of job satisfaction effects for both needs fulfilment and frustration. Our contribution accords with Deci and colleagues' claim that 'future research should examine both need supports and need thwarts' (Deci, Olafsen, and Ryan 2017, 38). Secondly, to the best of our knowledge and based on extant evidence (e.g. Van den Broeck et al. 2016), our trial is the first that uses separate operations for the need of feeling related to others based on different categories of others (Breaugh 2020; Grant 2007). Indeed, our discrete choice experiment breaks down the need for relatedness with one's job beneficiaries, peers, and supervisor.

The third contribution of our research is methodological and offers a rigorous attempt to test the external validity of findings by replicating the same design across public organizations. While presenting results from related research projects within the same work is common practice in disciplines such as general management and applied psychology, it is still rare in public administration and management. As 'replication sit[s] at the heart of scientific progress' (Walker, James, and Brewer 2017, 1), we move beyond sequential replication studies and discuss the findings from related trials in the context of the same work. This may prove valuable for scholars and practitioners alike.

Lastly, the findings from the public and large-scale samples in our research may prove very useful in complementing evidence on the relationship between psychological needs fulfilment and job satisfaction that is available in other disciplines and may be more concerned with workers in private organizations (Van den Broeck et al. 2016).

From a practical perspective, our work aids policy makers and public managers interested in improving the work context within organizations in an effort to enhance performance and public workers wellness. Our discrete choice experiments may encourage them to assessing policies or practices in terms of the degree to which those are likely to '(a) allow the employees to gain competencies and/or feel confident, (b) experience the freedom to experiment and initiate their own behaviours and not feel pressured and coerced to behave as directed, and (c) feel respect and belonging in relation to both supervisors and peers' (Deci, Olafsen, and Ryan 2017, 38).

\section{Limitations and future directions}

Our findings should be interpreted and used in light of the external validity limitations that are common to most experimental research. In particular, the generalizability of our results might be threatened by systematic differences between those who participated and their counterpart that opted out of the study. Therefore, our work is naturally prone to further testing through study replications (e.g. Walker et al. 2019). More precisely, replicating our discrete choice experiment across, for instance, public professionals in other countries, industries, and organizations, as well as using alternative constructs' operations - which may include continuous rather than binary outcome variables - holds the promise of assessing the generalizability of our findings. 
Furthermore, although 'there are several reasons to believe that conjoint analysis fares better than traditional survey experiments in terms of external validity' (Hainmueller, Hopkins, and Yamamoto 2014, 27), field experimentation would provide a definitive test about the generalizability of our findings beyond our online setting to real-life situations. Undoubtedly, while we followed best practices to build our conjoint experiment, there is no guarantee that this methodology maximizes ecological validity by fully capturing the complexity of preferences that drive realworld government employee choices. Complementing randomized experiments with other research designs such as observational data and qualitative inquiries would provide the opportunity to triangulate findings and gain a more nuanced understanding of how the fulfilment of psychological needs affects job satisfaction (Mele and Belardinelli 2019). Along the same lines of research design extensions, parallel designs (Imai, Tingley, and Yamamoto 2013) may be especially relevant to understand the causal process through which any outcomes come about.

The limitations of our study, thus, unveil avenues for future research. By hypothesizing that workplace contexts and individual differences influence work behaviours and health and wellness through the mediation of psychological needs and motivations, the basic self-determination theory model in the workplace (Deci, Olafsen, and Ryan 2017) naturally lends itself to future work that can disentangle the overall, direct, and indirect causal effects of the mediating factors. As suggested by an anonymous reviewer, such experimentations would nicely complement our findings and explore the how in addition to the what. Another research direction that seems worth pursuing relates to the interplay between person-environment fit and the fulfilment of basic psychological needs, so as to investigate how much variation in job satisfaction is explained by selfdetermination theory relative to other constructs. Furthermore, future research efforts should seek to improve and refine the measurement of basic psychological needs, with particular attention to the different dimensions of relatedness.

\section{Conclusion}

Understanding the causal relationship between the fulfilment of employees' psychological needs and job satisfaction is extremely relevant for managers in public institutions devoted to serving citizens efficiently and effectively. Indeed, fulfiling workers' psychological needs so to nurture their satisfaction will continue to be at the heart of practitioners' policy making in personnel administration. Scholars in our field can contribute to deepen and broaden this understanding through rigorous studies that show which interventions work, which do not, and why.

Our research attempts to reach this goal by making self-determination theory go public. More precisely, we experimentally test the link between the psychological needs and job satisfaction in a series of discrete choice experiments with large samples of public employees in mission-driven organizations. This allow us to unveil the extent to which healthcare professionals are willing to trade-off among autonomy, competence, and relatedness with different categories of beneficiaries to gain higher levels of job satisfaction. Our work may be valuable for human resource managers in the public sector and scholars in public administration who are interested in fulfiling employees' psychological needs to promote and sustain wellness and performance simultaneously. 


\section{Acknowledgments}

This study is part of a joined research project with the following two Italian regions: Regione Puglia, Regione del Veneto - Azienda Zero.

\section{Disclosure statement}

No potential conflict of interest was reported by the author(s).

\section{Notes on contributors}

R. Paul Battaglio, Jr. is Professor of public and non-profit management at the Public and nonprofit management program, School of Economic, political, and policy sciences at the University of Texas at Dallas and affiliate professor in the Institute of Management and EMbeDS of the Scuola Superiore Sant'Anna. He is also co-editor in chief of Public Administration Review. His research interests include public human resource management, organization theory, behavioural public administration, comparative public policy, and research methods. email: battaglio@utdallas.edu

Nicola Belle is Assistant professor at the Management and Healthcare Laboratory in the Institute of Management and EMbeDS, Scuola Superiore Sant'Anna, Pisa, Italy. His research focuses on behavioural public administration and management. email: nicola.belle@santannapisa.it

Paola Cantarelli is Assistant professor at the Management and Healthcare Laboratory in the Institue of Management and EMbeDS, Scuola Superiore Sant'Anna, Pisa, Italy. Her research focuses on behavioural management and work motivation in mission-driven organizations. email: paola.cantarelli@santannapisa.it

\section{ORCID}

R. Paul Battaglio (D) http://orcid.org/0000-0003-0826-912X

\section{References}

An, S.-H., K. J. Meier, J. Ladenburg, and N. Westergård-Nielsen. 2020. "Leadership and Job Satisfaction: Addressing Endogeneity with Panel Data from a Field Experiment." Review of Public Personnel Administration 40 (4): 589-612.

Battaglio, R. P., Jr, P. Belardinelli, N. Belle, and P. Cantarelli. 2019. "Behavioral Public Administration Ad Fontes: A Synthesis of Research on Bounded Rationality, Cognitive Biases, and Nudging in Public Organizations." Public Administration Review 79 (3): 304-320. doi:10.1111/puar.12994.

Belle, N. 2013. "Experimental Evidence on the Relationship between Public Service Motivation and Job Performance." Public Administration Review 73 (1): 143-153. doi:10.1111/j.1540-6210.2012.02621.x.

Belle, N. 2014. "Leading to Make A Difference: A Field Experiment on the Performance Effects of Transformational Leadership, Perceived Social Impact, and Public Service Motivation." Journal of Public Administration Research and Theory 24 (1): 109-136. doi:10.1093/jopart/mut033.

Belle, N., and P. Cantarelli. 2015. "Monetary Incentives, Motivation, and Job Effort in the Public Sector: An Experimental Study with Italian Government Executives." Review of Public Personnel Administration 35 (2): 99-123. doi:10.1177/0734371X13520460.

Belle, N., and P. Cantarelli. 2018a. "Randomized Experiments and Reality of Public and Nonprofit Organizations: Understanding and Bridging the Gap." Review of Public Personnel Administration 38 (4): 494-511. doi:10.1177/0734371X17697246.

Belle, N., and P. Cantarelli. 2018b. "The Role of Motivation and Leadership in Public Employees' Job Preferences: Evidence from Two Discrete Choice Experiments." International Public Management Journal 21 (2): 191-212. doi:10.1080/10967494.2018.1425229. 
Belle, N., and P. Cantarelli. 2019. "Do Ethical Leadership, Visibility, External Regulation, and Prosocial Impact Affect Unethical Behavior? Evidence from a Laboratory and a Field Experiment." Review of Public Personnel Administration 39 (3): 349-371. doi:10.1177/ $0734371 X 17721301$.

Bolino, M. C., and A. M. Grant. 2016. “The Bright Side of Being Prosocial at Work, and the Dark Side, Too: A Review and Agenda for Research on Other-oriented Motives, Behavior, and Impact in Organizations." The Academy of Management Annals 10 (1): 599-670. doi:10.5465/ 19416520.2016.1153260.

Breaugh, J. 2020. "Too Stressed to Be Engaged? The Role of Basic Needs Satisfaction in Understanding Work Stress and Public Sector Engagement.” Public Personnel Management. doi:10.1177/ 0091026020912516.

Breaugh, J., A. Ritz, and K. Alfes. 2018. "Work Motivation and Public Service Motivation: Disentangling Varieties of Motivation and Job Satisfaction." Public Management Review 20 (10): 1423-1443. doi:10.1080/14719037.2017.1400580.

Cantarelli, P., N. Belle, and F. Longo. 2020. "Exploring the Motivational Bases of Public Mission-driven Professions Using a Sequential-explanatory Design." Public Management Review 22 (19): 1535-1559.

Cantarelli, P., P. Belardinelli, and N. Belle. 2016. "A Meta-analysis of Job Satisfaction Correlates in the Public Administration Literature." Review of Public Personnel Administration 36 (2): 115-144. doi:10.1177/0734371X15578534.

Chen, C.-A., and B. Bozeman. 2013. "Understanding Public and Nonprofit Managers' Motivation through the Lens of Self-determination Theory." Public Management Review 15 (4): 584-607. doi:10.1080/14719037.2012.698853.

Chordiya, R., M. Sabharwal, and R. Paul Battaglio. 2019. "Dispositional and Organizational Sources of Job Satisfaction: A Cross-national Study." Public Management Review 21 (8): 1101-1124. doi:10.1080/14719037.2018.1544274.

Christensen, R. K., L. Paarlberg, and J. L. Perry. 2017. "Public Service Motivation Research: Lessons for Practice.” Public Administration Review 77 (4): 529-542. doi:10.1111/puar.12796.

Corduneanu, R., A. Dudau, and G. Kominis. 2020. "Crowding-in or Crowding-out: The Contribution of Self-determination Theory to Public Service Motivation.” Public Management Review 22 (7): 1070-1089. doi:10.1080/14719037.2020.1740303.

Deci, E. L., A. H. Olafsen, and R. M. Ryan. 2017. "Self-determination Theory in Work Organizations: The State of a Science." Annual Review of Organizational Psychology and Organizational Behavior 4: 19-43. doi:10.1146/annurev-orgpsych-032516-113108.

Deci, E. L., and R. M. Ryan. 2000. “The" What" and" Why" of Goal Pursuits: Human Needs and the Selfdetermination of Behavior.” Psychological Inquiry 11 (4): 227-268. doi:10.1207/S15327965PLI1104_01.

Fernandez, S., W. G. Resh, T. Moldogaziev, and Z. W. Oberfield. 2015. "Assessing the past and Promise of the Federal Employee Viewpoint Survey for Public Management Research: A Research Synthesis." Public Administration Review 75 (3): 382-394. doi:10.1111/puar.12368.

Grant, A. M. 2007. "Relational Job Design and the Motivation to Make a Prosocial Difference." Academy of Management Review 32 (2): 393-417. doi:10.5465/amr.2007.24351328.

Grimmelikhuijsen, S., S. Jilke, A. L. Olsen, and L. Tummers. 2017. "Behavioral Public Administration: Combining Insights from Public Administration and Psychology." Public Administration Review 77 (1): 45-56. doi:10.1111/puar.12609.

Hainmueller, J., D. Hangartner, and T. Yamamoto. 2015. "Validating Vignette and Conjoint Survey Experiments against Real-world Behavior." Proceedings of the National Academy of Sciences 112 (8): 2395-2400. doi:10.1073/pnas.1416587112.

Hainmueller, J., D. J. Hopkins, and T. Yamamoto. 2014. "Causal Inference in Conjoint Analysis: Understanding Multidimensional Choices via Stated Preference Experiments." Political Analysis 22 (1): 1-30. doi:10.1093/pan/mpt024.

Harrison, G. W., and J. A. List. 2004. “Field experiments.” Journal of Economic Literature 42(4): 10091055.

Horvath, L., S. Banducci, and O. James. 2020. "Citizens' Attitudes to Contact Tracing Apps.” Journal of Experimental Political Science 1-13. doi:10.1017/XPS.2020.30.

Imai, K., D. Tingley, and T. Yamamoto. 2013. "Experimental Designs for Identifying Causal Mechanisms." Journal of the Royal Statistical Society: Series A (Statistics in Society) 176 (1): 5-51. doi:10.1111/j.1467-985X.2012.01032.x. 
Jacobsen, C. B., J. Hvitved, and L. B. Andersen. 2014. "Command and Motivation: How the Perception of External Interventions Relates to Intrinsic Motivation and Public Service Motivation." Public Administration 92 (4): 790-806. doi:10.1111/padm.12024.

Jankowski, M., C. Prokop, and M. Tepe. 2020. "Representative Bureaucracy and Public Hiring Preferences: Evidence from a Conjoint Experiment among German Municipal Civil Servants and Private Sector Employees." Journal of Public Administration Research and Theory. 30: 596-618. Online first. doi:10.1093/jopart/muaa012.

Jensen, D. C., and L. B. Pedersen. 2017. "The Impact of Empathy-Explaining Diversity in Street-level Decision-making." Journal of Public Administration Research and Theory 27 (3): 433-449. doi:10.1093/jopart/muw070.

Jensen, U. T., and L. L. Bro. 2018. "How Transformational Leadership Supports Intrinsic Motivation and Public Service Motivation: The Mediating Role of Basic Need Satisfaction." The American Review of Public Administration 48 (6): 535-549. doi:10.1177/0275074017699470.

Jilke, S., G. G. Van Ryzin, and S. Van de Walle. 2016. "Responses to Decline in Marketized Public Services: An Experimental Evaluation of Choice Overload." Journal of Public Administration Research and Theory 26 (3): 421-432. doi:10.1093/jopart/muv021.

Jilke, S., and L. Tummers. 2018. "Which Clients are Deserving of Help? A Theoretical Model and Experimental Test." Journal of Public Administration Research and Theory 28 (2): 226-238. doi:10.1093/jopart/muy002.

Kim, S. 2005. "Individual-level factors and organizational performance in government organizations." Journal of Public Administration Research and Theory 15: 245-261.

Langer, J., M. K. Feeney, and S. E. Lee. 2019. "Employee Fit and Job Satisfaction in Bureaucratic and Entrepreneurial Work Environments." Review of Public Personnel Administration 39 (1): 135-155. doi:10.1177/0734371X17693056.

Lee, H.-W., P. J. Robertson, and K. Kim. 2020. "Determinants of Job Satisfaction among US Federal Employees: An Investigation of Racial and Gender Differences." Public Personnel Management 49 (3): 336-366.

Linos, E. 2018. "More than Public Service: A Field Experiment on Job Advertisements and Diversity in the Police." Journal of Public Administration Research and Theory 28 (1): 67-85. doi:10.1093/ jopart/mux032.

Locke, E. A. 1976. "The nature and cause of job satisfaction." In M. D. Dunnette (Ed.), Handbook of industrial and organizational psychology (pp. 1297-1343). Chicago, IL: Rand McNally.

Marvel, J. D., and W. G. Resh. 2018. "An Unconscious Drive to Help Others? Using the Implicit Association Test to Measure Prosocial Motivation.” International Public Management Journal. doi:10.1080/10967494.2018.1471013.

Mele, V., and P. Belardinelli. 2019. "Mixed Methods in Public Administration Research: Selecting, Sequencing, and Connecting." Journal of Public Administration Research and Theory 29 (2): 334-347. doi:10.1093/jopart/muy046.

Mergel, I., N. Belle, and G. Nasi. 2019. "Prosocial Motivation of Private Sector IT Professionals Joining Government.” Review of Public Personnel Administration. Online first. 0734371X19886058.

Meyer-Sahling, J., K. Mikkelsen, and C. Schuster. 2020. "Merit Recruitment, Tenure Protections and Public Service Motivation: Evidence from a Conjoint Experiment with 7,300 Public Servants in Latin America, Africa and Eastern Europe." Public Administration. Accepted article. doi:10.1111/ padm.12708.

Meyer-Sahling, J.-H., K. S. Mikkelsen, and C. Schuster. 2019. "The Causal Effect of Public Service Motivation on Ethical Behavior in the Public Sector: Evidence from a Large-scale Survey Experiment." Journal of Public Administration Research and Theory 29 (3): 445-459. doi:10.1093/ jopart/muy071.

Morton, R., and K. Williams. 2010. "From Nature to the Lab: The Methodology of Experimental Political Science and the Study of Causality." Cambridge University Press.

(OCED) Organization for Economic Cooperation and Development. 2016. "Engaging Public Employees for a High-Performing Civil Service." OECD Public Governance Reviews. Paris: OECD Publishing.

Perry, J. L., A. Hondeghem, and L. R. Wise. 2010. "Revisiting the Motivational Bases of Public Service: Twenty Years of Research and an Agenda for the Future." Public Administration Rreview 70 (5): 681-690. doi:10.1111/j.1540-6210.2010.02196.x. 
Perry, J. L., and L. R. Wise. 1990. “The Motivational Bases of Public Service.” Public Administration Review 50 (3): 367-373. doi:10.2307/976618.

Rainey, H. G. 2009. Understanding and Managing Public Organizations. San Francisco, CA: John Wiley.

Ritz, A., G. A. Brewer, and O. Neumann. 2016. "Public Service Motivation: A Systematic Literature Review and Outlook." Public Administration Review 76 (3): 414-426. doi:10.1111/puar.12505.

Ryan, M., J. Kolstad, P. Rockers, and C. Dolea. 2012. "How to Conduct a Discrete Choice Experiment for Health Workforce Recruitment and Retention in Remote and Rural Areas: A User Guide with Case Studies." World Health Organization \& CapacityPlus: World Bank.

Schuster, C., M. Jan-Hinrik, and K. S. Mikkelsen. 2020. "(Un) Principled Principals,(un) Principled Agents: The Differential Effects of Managerial Civil Service Reforms on Corruption in Developing and OECD Countries." Governance 33 (4): 829-848. doi:10.1111/gove.12461.

Shadish, W. R., T. D. Cook, and D. T. Campbell. 2002. Experimental and Quasi-Experimental Designs for Generalized Causal Inference. Boston: Houghton Mifflin.

Smith, P. C., L. M. Kendall,and C. L. Hulin. 1969. "The measurement of satisfaction in work and retirement."Chicago, IL: Rand McNally.

Steijn, B., and J. van der Voet. 2019. "Relational Job Characteristics and Job Satisfaction of Public Sector Employees: When Prosocial Motivation and Red Tape Collide." Public Administration 97 (1): 64-80. doi:10.1111/padm.12352.

Street, D. J., L. Burgess, and J. J. Louviere. 2005. "Quick and Easy Choice Sets: Constructing Optimal and Nearly Optimal Stated Choice Experiments." International Journal of Research in Marketing 22 (4): 459-470. doi:10.1016/j.ijresmar.2005.09.003.

Van den Broeck, A. D., L. Ferris, C.-H. Chang, and C. C. Rosen. 2016. "A Review of Self-determination Theory's Basic Psychological Needs at Work.” Journal of Management 42 (5): 1195-1229. doi:10.1177/0149206316632058.

Van Puyvelde, S., R. Caers, C. Du Bois, and M. Jegers. 2016. "Managerial Objectives and the Governance of Public and Non-profit Organizations." Public Management Review 18 (2): 221-237. doi:10.1080/14719037.2014.969760.

Vandenabeele, W. 2007. "Toward a Public Administration Theory of Public Service Motivation: An Institutional Approach.” Public Management Review 9 (4): 545-556. doi:10.1080/14719030701726697.

Vandenabeele, W. 2014. "Explaining Public Service Motivation: The Role of Leadership and Basic Needs Satisfaction." Review of Public Personnel Administration 34 (2): 153-173. doi:10.1177/ $0734371 X 14521458$.

Vigan, F. A., and D. Giauque. 2018. "Job Satisfaction in African Public Administrations: A Systematic Review." International Review of Administrative Sciences 84 (3): 596-610. doi:10.1177/ 0020852316651693.

Walker, R. M., G. A. Brewer, M. Jin Lee, N. Petrovsky, and A. Van Witteloostuijn. 2019. "Best Practice Recommendations for Replicating Experiments in Public Administration." Journal of Public Administration Research and Theory 29 (4): 609-626. doi:10.1093/jopart/muy047.

Walker, R. M., O. James, and G. A. Brewer. 2017. "Replication, Experiments and Knowledge in Public Management Research.” Public Management Review 19: 1221-1234. doi:10.1080/ 14719037.2017.1282003.

Wright, B. E., and A. M. Grant. 2010. "Unanswered Questions about Public Service Motivation: Designing Research to Address Key Issues of Emergence and Effects." Public Administration Review 70 (5): 691-700. doi:10.1111/j.1540-6210.2010.02197.x.

Yang, K., and A. Kassekert. 2009. "Linking Management Reform with Employee Job Satisfaction: Evidence from Federal Agencies." Journal of Public Administration Research and Theory 20 (2): 413-436. doi:10.1093/jopart/mup010.

Zhu, L., C. Witko, and K. J. Meier. 2019. "The Public Administration Manifesto II: Matching Methods to Theory and Substance." Journal of Public Administration Research and Theory 29 (2): 287-298. doi:10.1093/jopart/muy079. 


\section{Appendix A. Example of 2 of 32 choice sets in our DCEs}

Choice set 1. In which of these two workplace scenarios, X or Y, would you feel more satisfied?.

\begin{tabular}{ll}
\hline Workplace $X$ & \multicolumn{1}{c}{ Workplace $Y$} \\
\hline $\begin{array}{l}\text { You have high decision-making autonomy. } \\
\text { You do not have the competence to carry out successfully } \\
\text { some of the tasks required by your job. }\end{array}$ & $\begin{array}{c}\text { You have low decision-making autonomy. } \\
\text { successfully all the tasks required by your job. } \\
\text { Your job has a positive impact on a few clients. }\end{array}$ \\
$\begin{array}{l}\text { Your job has a positive impact on many clients. } \\
\text { You are satisfied with the relationship with your peers. } \\
\text { You are little satisfied with the relationship with your } \\
\text { supervisor. }\end{array}$ & $\begin{array}{c}\text { You poure satisfied with the relationship with your } \\
\text { supervisor. }\end{array}$ \\
\hline
\end{tabular}

Choice set 2. In which of these two workplace scenarios, X or Y, would you feel more satisfied?.

\begin{tabular}{|c|c|}
\hline Workplace X & Workplace Y \\
\hline You have low decision-making autonomy. & You have high decision-making autonomy. \\
\hline $\begin{array}{l}\text { You have the competence to carry out } \\
\text { successfully all the tasks required by your job. }\end{array}$ & $\begin{array}{l}\text { You do not have the competence to carry out successfully } \\
\text { some of the tasks required by your job. }\end{array}$ \\
\hline Your job has a positive impact on many clients. & Your job has a positive impact on a few clients. \\
\hline $\begin{array}{l}\text { You are little satisfied with the relationship with } \\
\text { your peers. }\end{array}$ & You are satisfied with the relationship with your peers. \\
\hline $\begin{array}{l}\text { You are little satisfied with the relationship with } \\
\text { your supervisor. }\end{array}$ & $\begin{array}{l}\text { You are satisfied with the relationship with your } \\
\text { supervisor. }\end{array}$ \\
\hline
\end{tabular}

\section{Appendix B. Unstandardized coefficients from the conditional logit, by psychological needs, by DCE}

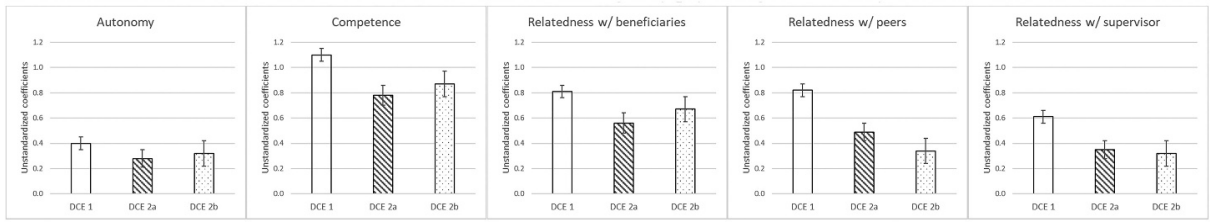

Error bars represent standard errors. 